\title{
Comment pieces of 2016
}

Our editors' pick of this year's influential expert opinions.

15 December 2016

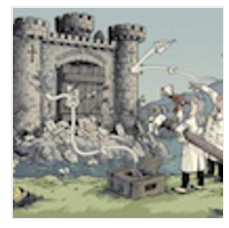

Reproducibility: A tragedy of errors

Mistakes in peer-reviewed papers are easy to find but hard to fix, report David B. Allison and colleagues. 3 February 2016

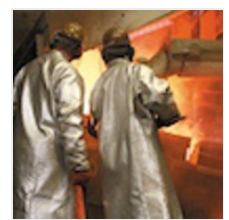

The circular economy

A new relationship with our goods and materials would save resources and energy and create local jobs, explains Walter R. Stahel.

23 March 2016

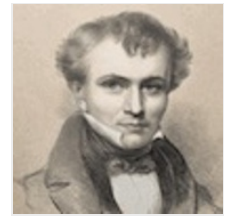

Peer review: Troubled from the start

Pivotal moments in the history of academic refereeing have occurred at times when the public status of science was being renegotiated, explains Alex Csiszar.

19 April 2016

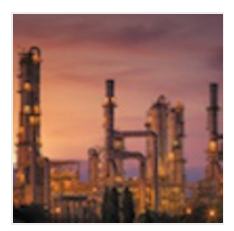

Seven chemical separations to change the world

Purifying mixtures without using heat would lower global energy use, emissions and pollution - and open up new routes to resources, say David S. Sholl and Ryan P. Lively.

26 April 2016

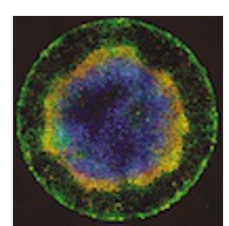

Embryology policy: Revisit the 14-day rule

Studies of human development in vitro are on a collision course with an international policy that limits embryo research to the first two weeks of development, warn Insoo Hyun, Amy Wilkerson and Josephine Johnston.

4 May 2016

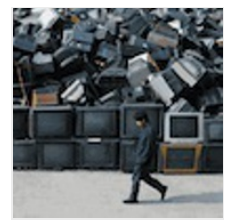

Take responsibility for electronic-waste disposal

International cooperation is needed to stop developed nations simply offloading defunct electronics on developing countries, argue Zhaohua Wang, Bin Zhang and Dabo Guan.

3 April 2016

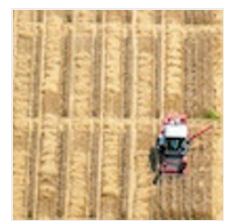

Agricultural R\&D is on the move

Big shifts in where research and development in food and agriculture is carried out will shape future global food production, write Philip G. Pardey and colleagues.

14 September 2016

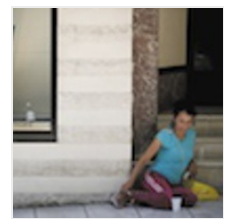

End class wars

Mike Savage calls on sociologists to resolve their differences over definitions of social class to allow better analyses of inequality.

21 September 2016

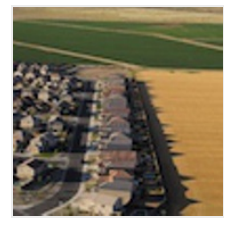

Where to put the next billion people

Richard T. T. Forman and Jianguo Wu call for global and regional approaches to urban planning.

28 September 2016

Genomics is failing on diversity

An analysis by Alice B. Popejoy and Stephanie M. Fullerton indicates that some populations are still being left behind on the road to precision medicine.

12 October 2016 


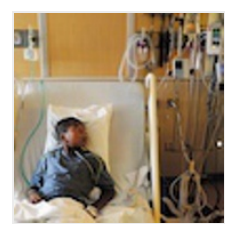

Nature I doi:10.1038/nature.2016.21181 